\title{
Comprehensive tobacco marketing restrictions: promotion, packaging, price and place
}

\author{
Lisa Henriksen
}

\begin{abstract}
Correspondence to
Dr Lisa Henriksen, Stanford

Prevention Research Center, Stanford University School of Medicine, 1070 Arastradero Road, Suite 353, Palo Alto, California 94304, USA; Ihenriksen@stanford.edu
\end{abstract}

Received 31 December 2011 Accepted 8 January 2012

\begin{abstract}
Evidence of the causal role of marketing in the tobacco epidemic and the advent of the WHO Framework Convention on Tobacco Control have inspired more than half the countries in the world to ban some forms of tobacco marketing. This paper briefly describes the ways in which cigarette marketing is restricted and the tobacco industry's efforts to subvert restrictions. It reviews what is known about the impact of marketing regulations on smoking by adults and adolescents. It also addresses what little is known about the impact of marketing bans in relation to concurrent population-level interventions, such as price controls, anti-tobacco media campaigns and smoke-free laws. Point of sale is the least regulated channel and research is needed to address the immediate and long-term consequences of policies to ban retail advertising and pack displays. Comprehensive marketing restrictions require a global ban on all forms of promotion, elimination of packaging and price as marketing tools, and limitations on the quantity, type and location of tobacco retailers.
\end{abstract}

Tobacco industry marketing is one cause of the global spread of tobacco use and addiction. The content and quantity of marketing serve to promote experimentation with smoking, increase tobacco consumption, discourage quitting and encourage relapse. ${ }^{1}$ In addition, the industry's systematic targeting of population subgroups fosters the socioeconomic and racial/ethnic disparities that characterise tobacco use patterns in many countries. For these reasons, WHO identifies bans on advertising, promotion and sponsorship among the steps required to address the global tobacco epidemic. $^{2}$ By 2009, more than 100 countries had banned some form of tobacco marketing. ${ }^{3}$

This paper briefly describes the ways in which cigarette marketing is restricted and the tobacco industry's efforts to subvert such regulation. In order to examine what is known about the efficacy of marketing restrictions, relevant literature was identified from a search of PubMed, PsycInfo and Web of Science using the terms advertising, labelling, marketing, outlets, packaging, price, point of sale, promotion, retailers, in combination with ban, policy, regulation or restriction, and with cigarette, smoking or tobacco. The results were limited to English language publications since 2000 and available for review prior to August 2011. This narrative review is organised according to four elements of an integrated marketing effort that should inform comprehensive regulation: promotion, packaging, price and place. ${ }^{1}$ Promotion refers to direct advertising (broadcast and print media, billboards/ outdoor and point of sale) and indirect advertising in the form of cigarette-branded merchandise, free tobacco products and sponsorship. Restrictions pertaining to 'new' media are described elsewhere in this special issue. Packaging refers to product presentation, including attributes of branding (logo, colour, descriptors) and functional design (size, shape, opening). Price refers to wholesale and retail pricing and, in this paper, includes strategies to reduce prices at the point of sale. Place refers to the distribution channels that tobacco companies use to make their products available to the public, primarily through retailers. Restrictions on promotion, packaging and price aim to reduce consumer demand for tobacco products. However, comprehensive marketing regulation should also address restrictions on place, which aim to reduce the supply and availability of tobacco products.

Analyses of internal industry documents reveal a standard set of tactics used to thwart marketing regulation: adopting weak voluntary advertising codes to avoid stronger measures, hiring consultants to discredit the evidence base for restrictions, using third-party companies to lobby against marketing restrictions, delaying or weakening their implementation with protracted litigation, and publicising imaginary barriers to enforcement in order to undermine public support and political will. ${ }^{4-7}$ In opposition to Australia's plain packaging legislation, for example, transnational tobacco companies threatened protracted litigation for violation of international trade law and claimed that implementation would be burdensome for merchants and customers, increase opportunity for theft and diminish retailer profits. The industry uses these same arguments to oppose pack display bans. ${ }^{8} 9$ Singapore, the first country to restrict tobacco advertising, provides another illustrative example. In order to circumvent the restrictions, Philip Morris introduced a new cigarette brand by first promoting a wine cooler with the same name, and tobacco companies increased investment in Malaysian television advertising in order to reach consumers in Singapore. ${ }^{10}$ After Singapore limited retail displays to one pack front per brand variation, tobacco companies focused on special offers, novel packaging and innovative display units to maximise the remaining marketing opportunities at the point of sale. Indeed, wherever legislated bans are enacted, the industry exploits opportunities for crossborder marketing and shifts promotional efforts to unregulated channels, such as sponsorship, brand stretching and point of sale. ${ }^{11}$

\section{PROMOTION}

This section considers the impact of advertising bans on exposure to tobacco marketing and on 
tobacco use. It also addresses what is known about the impact of the bans in relation to concurrent population-level policy interventions. Table 1 summarises the proportion of countries that ban various forms of advertising, promotion and sponsorship as reported by WHO. It also compares restrictions in the world's largest cigarette markets, as well as Australia and the UK. As defined by the WHO Framework Convention on Tobacco Control (FCTC), a 'comprehensive' ban pertains to direct advertising (broadcast and print media, billboards/outdoor and point of sale), as well as indirect advertising, including distribution of free tobacco products (sampling), promotional discounts, nontobacco products identified with tobacco brand names (brand stretching), tobacco products identified with non-tobacco brand names (brand sharing), industry-sponsored events and the appearance of tobacco products in television or films. ${ }^{15} \mathrm{WHO}$ estimates that 19 countries and $6 \%$ of the world's population benefit from a 'comprehensive' ban on tobacco marketing. ${ }^{3}$ Unfortunately, these are overestimates because so few countries ban pack displays at the point of sale, which are functionally equivalent to advertising and similarly influence smoking. ${ }^{16}$

Two of the largest cigarette markets, Indonesia and the USA, have not ratified the FCTC. In Indonesia, weak regulation of tobacco marketing does not comply with FCTC guidelines regarding advertising, promotion and sponsorship. ${ }^{17}$ In the USA, the 2009 Family Smoking Prevention and Tobacco Control Act (FSPTCA) authorises the US Food and Drug Administration (FDA) to regulate tobacco products, including their marketing, distribution and sale. ${ }^{18}$ Consistent with FCTC guidelines (Article 13), ${ }^{15}$ the FSPTCA prohibited non-tobacco brand gifts with purchase and tobacco-brand sponsorship of sports and entertainment events. Weaker provisions permit self-service displays and free samples of tobacco products in facilities that restrict access to adults. Tobacco companies sought injunction for other provisions: limiting advertising to black-and-white text, requiring pictorial health warnings on advertising and prohibiting outdoor advertisements near schools and playgrounds (all pending appeal as of this writing). ${ }^{19}$ Further regulation may result from the expanded authority of state and local governments to restrict the time, place and manner, but not the content, of tobacco marketing.

\section{Reductions in exposure}

Adult smokers' awareness of tobacco marketing reflects objective differences in regulations between countries 132021 and is sensitive to policy change within countries. ${ }^{22-24}$ For example, months after the UK banned most forms of advertising, promotion and sponsorship, awareness of marketing decreased in the regulated channels, and more so than in Australia, Canada and the USA, where the ban was not enforced. ${ }^{23}$ Although the rate of decline tapered over subsequent years, the differences between marketing exposure among smokers in the UK and the other three countries persisted. ${ }^{13}$

Adolescents' exposure to tobacco marketing is also sensitive to policy change within countries and underscores the importance of including point of sale in comprehensive regulation. Like adult smokers, adolescents reported greater declines in awareness of marketing shortly after the UK ban, and more so in regulated than in unregulated channels, such as smoking in movies/ television, cigarette-branded clothing, in-store advertising and displays. ${ }^{25}$ Just 2 years after Hong Kong supplemented a ban for broadcast media and billboards with a ban for print media, a smaller proportion of children (ages 8-10) recognised tobacco

Table 1 Restrictions on advertising, promotion and sponsorship compared for large cigarette markets and as a proportion of all countries; In some cases, a partial ban may reflect variation in subnational policies; for example, Australia and Canada banned retail advertising and pack displays at different times in different areas and In other cases, partial bans reflect limitations on content or placement, such as a prohibition on advertising in magazines with a large youth readership in the USA and Russia (see footnotes for specific examples).

\begin{tabular}{|c|c|c|c|c|c|c|c|c|c|c|c|}
\hline \multicolumn{11}{|c|}{ Countries } & \multirow{2}{*}{$\begin{array}{c}\begin{array}{c}\text { Complete ban } \\
\text { defined by WHO }\end{array} \\
\begin{array}{c}\text { \% of } 194 \\
\text { countries }^{14}\end{array} \\
\end{array}$} \\
\hline Restrictions & Australia的13 & Brazil ${ }^{12}$ & Canada $^{12} 13$ & China $^{12}$ & India $a^{12}$ & Indonesia $^{12}$ & $J^{J} p^{14}$ & Russia $^{12}$ & $\mathrm{UK}^{1314}$ & USA $\mathrm{A}^{1314}$ & \\
\hline \multicolumn{12}{|l|}{ Advertising (direct) } \\
\hline Television/radio, domestic & 0 & - & - & - & 0 & 0 & 0 & 0 & 0 & 0 & $69.3 \%$ \\
\hline $\begin{array}{l}\text { Television/radio, } \\
\text { international }\end{array}$ & 0 & - & 0 & - & $\theta$ & 0 & 0 & - & 0 & 0 & NR \\
\hline $\begin{array}{l}\text { Magazine/newspaper, } \\
\text { domestic }\end{array}$ & - & - & - & - & - & 0 & 0 & 0 & ○ & 0 & $55.7 \%$ \\
\hline $\begin{array}{l}\text { Magazine/newspaper, } \\
\text { international }\end{array}$ & 0 & - & 0 & - & - & 0 & 0 & 0 & 0 & 0 & NR \\
\hline Outdoor (billboard/transit) & - & - & 0 & 0 & 0 & 0 & 0 & - & - & 0 & $58.3 \%$ \\
\hline Direct mail & $\theta$ & - & 0 & 0 & e & 0 & NR & 0 & 0 & 0 & NR \\
\hline Point of sale, advertising & $\theta$ & 0 & O* & 0 & 0 & 0 & 0 & 0 & $\theta$ & 0 & $30.7 \%$ \\
\hline Point of sale, pack displays & $\theta$ & 0 & $\theta^{+}$ & 0 & 0 & 0 & $\mathrm{NR}$ & $\theta$ & $O \neq$ & 0 & NR \\
\hline \multicolumn{12}{|l|}{ Advertising (indirect) } \\
\hline Branded merchandise & - & - & 0 & 0 & - & 0 & 0 & 0 & - & - & $40.1 \%$ \\
\hline Free distribution of tobacco & $\theta$ & e & e & 0 & 0 & - & 0 & 0 & e & $\theta$ & $47.9 \%$ \\
\hline Promotional discounts & 0 & - & - & 0 & - & 0 & - & 0 & - & 0 & $40.6 \%$ \\
\hline Sponsored events & \& & 0 & \& 8 & 0 & 0 & $\theta$ & 0 & 0 & 0 & 0 & $47.9 \%$ \\
\hline
\end{tabular}

= complete ban $\mathrm{O}=$ partial ban $\mathrm{O}=$ no ban $\quad \mathrm{NR}=$ not reported

Data sources are given in the reference list.

*Campaign for Tobacco-Free Kids (CTFK) regards Canada's ban on point-of-sale advertising as a partial ban because the Tobacco Act permits signs in places where persons under 18 years are not permitted. Point-of-sale advertising is not allowed in other retail establishments.

tCTFK regards Canada's ban on point-of-sale pack displays as a partial ban because it does not apply to tobacconist shops or duty free stores.

$\ddagger$ The ban on pack displays in the UK will be implemented in small stores by April 2012 and in large stores by April 2015.

$\S$ Australia and Canada permit financial sponsorship, but the public acknowledgement of that support is restricted. CTFK regards this as a partial ban. 
brand names and logos; however, brand recognition remained prevalent $30 \%$ to $64 \%$ among children whose family were nonsmokers) because point-of-sale advertising and sponsorship were not controlled. ${ }^{26}$ Two decades after Norway banned advertising in traditional media, adolescents' (ages 13-15) self-reported exposure indicated market penetration in multiple channels, particularly branded promotional items and point of sale. ${ }^{27}$ The persistent association of exposure and intention to smoke under legislated bans suggests that even limited exposure among adolescents remains a cause for concern. ${ }^{25} 27$

\section{Other intermediate outcomes}

Marketing restrictions are expected to benefit prevention and cessation efforts by reducing environmental cues to smoke and by altering the cognitive responses to marketing that predispose individuals to smoke. ${ }^{28}$ Exposure is an important marker of the success of legislated bans 2930 and it is one of the few intermediate outcomes measured in multicountry surveillance surveys (see table 2).

Some intermediate outcomes change within a short time of policy enforcement. For example, evidence from longitudinal surveys suggests that within months after the UK banned advertising and Ireland banned advertising and pack displays, fewer adolescents (ages 13-15) overestimated smoking prevalence among peers. ${ }^{22} 25$ This and other perceptions and attitudes-receptivity to tobacco marketing, positive outcome expectations, perceived access and approval, as well as anticipated difficulty of quitting-should be addressed by global surveillance systems.

\section{Reductions in population-level tobacco use}

Econometric studies illustrate differential effects of comprehensive and limited advertising bans on tobacco consumption:

Table 2 Assessment of tobacco marketing exposure and other intermediate outcomes of marketing regulation in multicountry surveillance surveys

\begin{tabular}{|c|c|c|c|}
\hline Exposure measures & GYTS $^{31}$ & GATS $^{32}$ & ITC- $4^{33}$ \\
\hline \multicolumn{4}{|l|}{ Advertising (direct) } \\
\hline Television/radio & $2^{*}$ & 0 & $1 \dagger \neq$ \\
\hline Magazine/newspaper & 2 & 0 & 1 \\
\hline Outdoor & 2 & 0 & 1 \\
\hline Direct mail & 0 & 1 & $1 \neq$ \\
\hline Point of sale, advertising & 0 & 1 & $1 \neq$ \\
\hline Point of sale, pack displays & 0 & 0 & 1 \\
\hline \multicolumn{4}{|l|}{ Advertising (indirect) } \\
\hline Branded merchandise & 1 & 1 & 1 \\
\hline Free tobacco products & 1 & 1 & $1 \neq$ \\
\hline Sponsored events & 0 & 0 & 1 \\
\hline \multicolumn{4}{|l|}{ Price promotion } \\
\hline Coupons & 0 & 1 & $1 \neq$ \\
\hline Discounts & 0 & 1 & 1 \\
\hline Gifts with purchase & 0 & 1 & 1 \\
\hline \multicolumn{4}{|l|}{ Other intermediate outcomes } \\
\hline Difficulty of quitting & 2 & 0 & 2 \\
\hline Perceived access & 0 & 0 & 0 \\
\hline Perceived approval & 0 & 0 & 0 \\
\hline Perceived prevalence & 0 & 0 & 0 \\
\hline Positive outcome expectations & 2 & 0 & 2 \\
\hline Receptivity to tobacco marketing & 0 & 0 & 0 \\
\hline
\end{tabular}

Cell entries: $0=$ unmeasured, $1=$ discrete measure, $2=$ frequency measure.

*Television only.

†Radio only

¥Measured for a subset of countries.

GYTS, Global Youth Tobacco Survey; GATS, Global Adult Tobacco Survey;

ITC-4, International Tobacco Control Four Country Survey (Australia, Canada, UK, USA).
In developed nations, comprehensive, but not limited, advertising bans reduced per capita consumption by approximately $7 \%{ }^{29}{ }^{34}$ In developing countries, comprehensive bans reduced per capita consumption by $24 \%$ and limited bans by $14 \%$, which suggests that advertising bans could have a greater impact in developing countries than elsewhere. ${ }^{34}$

Smoking prevalence has generally decreased among adults and adolescents in developed countries that adopted advertising bans. $^{35-37}$ In Brazil, decreases in lifetime smoking and heavy smoking among youth (ages 11-18) were observed in 8 of the 10 cities that were surveyed 2 years after the country banned advertising in all domestic media. ${ }^{37}$ Similarly, US restrictions on billboard and magazine advertising, branded promotional items and sponsored events coincided with declines in lifetime and past-month smoking by adolescents after 10 consecutive years of increasing rates. ${ }^{38}$ Of course, such ecological evidence cannot rule out the effects of other influences on smoking prevalence, including secular trends, economic changes, or concurrent policy interventions. Indeed, it is difficult to isolate the impact of marketing regulations because they are typically national in scope and implemented in concert with other measures, such as price controls, mass-media campaigns and smoke-free laws.

The few studies to address this topic suggest that strong advertising bans are second only to price policies in their impact on adult smoking. ${ }^{39} 40$ For example, a simulation model designed to explain change in smoking prevalence in Thailand attributed $61 \%$ of the decline in smoking among men to tax increases, $22 \%$ of the decline to a strong advertising ban, and the remainder to smoke-free laws, a media campaign and health warnings. ${ }^{40}$ Using a scoring system ${ }^{41}$ to rate the quality of tobacco control policies in 18 European countries, the study by Schaap et al suggested that price policies were the strongest correlate of overall quit ratios. ${ }^{39}$ In addition, stronger advertising bans were associated with higher quit ratios for gender and age groups with high education, and were the only policy correlates of quit ratios among men (ages 25-39) with low education.

A few studies of individual-level outcomes focus primarily on adolescent smoking in high-income countries, and provide little evidence as yet that existing bans are sufficient to reduce the odds of being a current smoker. ${ }^{42} 43$ The odds of regular smoking by 15 year olds in 29 European countries was not correlated with the strength of advertising bans, adjusting for other countrylevel policies and individual differences. ${ }^{42}$ In Australia, stronger restrictions on point-of-sale marketing predicted higher odds of past-month smoking by adolescents (ages $12-17) .{ }^{43}$ The authors noted that industry tactics to circumvent regulation, particularly the introduction of larger pack displays with more brand variations, could explain the counterintuitive finding.

In summary, a global marketplace for tobacco products and the industry's hydra-headed strategy to circumvent regulation has made it impossible to extinguish exposure to all forms of advertising, sponsorship and promotion. Bans significantly reduced exposure among adult smokers and adolescents in regulated channels. Observed decreases in smoking prevalence and associations with quit ratios confirm the importance of strong advertising bans for tobacco control. Evidence suggests that these policies also could diminish some of the cognitive responses that predispose individuals to smoke. ${ }^{22} 25$

\section{PACKAGING}

Pack design serves a critical role in tobacco marketing, particularly as other channels are restricted. ${ }^{44}$ In order to communicate with current and future smokers, the tobacco industry exploits all elements of packaging, including the construction, outer film, 
tear tape, inner frame, pack inserts and onserts. ${ }^{45}$ Branding information competes with pictorial warning labels for consumer attention in more than 40 countries, but not yet in several of the world's largest cigarette markets, including China, Japan, Russia and the USA. ${ }^{3}$ The FSPTCA requires that textonly health warnings cover $30 \%$ (front and back) of packaging for smokeless tobacco products, but US tobacco companies sought to block pictorial health warnings covering 50\% (top front and back) of cigarette packages (appeal pending as of this writing). ${ }^{19}$ The importance and efficacy of pictorial warnings, which are required by the FCTC guidelines (Article 11), are reviewed elsewhere. ${ }^{46}$

\section{Deceptive descriptors}

A total of 91 countries, including the USA, prohibit the misleading terms 'light', 'mild' and 'low tar' on cigarette packaging, as required by the FCTC (Article 11) and the FSPTCA. 318 Evidence from high-income and low-income countries describes significant declines in adult smokers' beliefs that 'light' cigarettes deliver less tar, are less harmful or easier to quit. ${ }^{47} 48$ In Thailand, the labelling restriction significantly reduced the proportion of adult smokers who agreed that 'light cigarettes are less harmful', and the impact was most pronounced among the lowest socioeconomic group. ${ }^{48}$ Smaller reductions were observed in high-income countries, where false beliefs were lower to start, and the effects decayed over time. ${ }^{47}$ In spite of the labelling restriction, approximately $20 \%$ of adult smokers in high-income countries reported that 'some cigarettes could be less harmful than others', ${ }^{49}$ and 39\% of adult smokers in Thailand reported that 'light' cigarettes were less harmful. ${ }^{48}$ In order to circumvent the regulation, tobacco companies replaced the banned terms with similarly deceptive words (eg, 'smooth') or numbers, manipulated the thickness of packaging to indicate that soft packs contained lighter/milder cigarettes than hard packs, ${ }^{48}$ and used lighter pack colours to signify lower strength. ${ }^{50}$ In many countries including the USA, tobacco companies substituted blue packaging for 'mild', gold for 'light' and silver for 'ultralight' brands. ${ }^{50} 51$ It is evident that consumers accept colour variation and other cues as indicators of reduced risk 4951 and that further regulation is needed to eliminate the misconception that some cigarettes are less harmful than others.

\section{Plain packaging}

Policies that seek to ban the use of trademarks, logos and other brand imagery from packaging would minimise tobacco companies' ability to cultivate false impressions that any cigarette brand is less hazardous to health. ${ }^{52}$ With a standardised shape, method of opening and background colour, the only distinguishing feature of packs would be brand and product variant names in a uniform style, colour and position. ${ }^{8}$ Given the industry's long-held objective to prevent plain packaging in any market, evidence about the anticipated benefits of plain packaging is primarily limited to experiments involving subjective ratings by young adult smokers and adolescents. ${ }^{8} 52$ Notable exceptions have used eye tracking to demonstrate increased visual attention towards the warning information and away from the brand information ${ }^{53}$ and experimental auctions to assess the potential impact of graphic warnings on consumer demand. ${ }^{54}$ The adoption of plain packaging in Australia (anticipated in 2012) will create the first opportunity for policy evaluation. In addition, further experimental research that features autonomic responses and behavioural indicators of attention or implicit attitudes would be informative.
This section focused narrowly on regulation of packaging, but marketing restrictions must also address what comes inside the box. Indeed, the FCTC (Articles 9 and 10) restricts the use of flavoured additives in cigarettes and some other tobacco products. ${ }^{15}$ Although the FSPTCA restriction is limited to cigarettes and excludes menthol flavouring, the FDA should strengthen this regulation in order to protect the public. ${ }^{55}$ Other design features of tobacco products (eg, coloured cigarette paper, gold tipping, heart-shaped filters, novel filtration systems) and related marketing efforts have similar potential to encourage product trial and to attract specific target groups, especially youth. ${ }^{1}$ Enhanced surveillance is needed to identify new product designs and to inform more comprehensive marketing restrictions.

\section{PRICE}

This section considers non-tax mechanisms to control tobacco prices. Marketing expenditure data from the USA illustrate the growing importance of price discounts. The proportion of annual marketing budget spent to reduce retail cigarette price increased from $60 \%$ in 1988 (the first year that coupons and retail value added were reported) to $88 \%$ in $2008 .{ }^{56}$ The 2008 spending was equivalent to approximately US\$160 per adult smoker in the USA. Among the 13 countries that have reported results of the 2009 Global Adult Tobacco Survey, the maximum proportion of adult smokers (age 15 or older) who noticed sale prices for cigarettes was $11 \%$ in the Philippines, and in Bangladesh, $8 \%$ noticed coupons and $16 \%$ noticed free gifts with purchase. $^{57}$ FCTC guidelines recommend banning all these forms of price promotion. ${ }^{15}$

Although 78 countries ban promotional discounts (see table 1), evaluation of these restrictions has been limited to high-income countries. For example, adult smokers' awareness of special price offers decreased more dramatically in the UK, where such discounts were banned, than in Australia, Canada and the USA, where partial or no bans existed. ${ }^{23}$ These differences persisted over several years, ${ }^{13}$ but the specific impact of such regulation on purchase patterns and consumption was not examined. Because lower prices promote consumption and deter quitting, eliminating retail value added programmes, such as buy-one-get-one-free offers, and prohibiting the distribution or redemption of coupons are recommended. ${ }^{58} 59$ Tobacco companies collect personal data from responses to special offers at stores and sponsored events, and from company websites with poor age-verification systems. ${ }^{60}$ Eliminating exclusions for direct mail would restrict the distribution of discount offers and weaken the industry's ability to cultivate long-term relationships with individual customers.

Regulations to prevent wholesalers and retailers from selling tobacco products below a fixed price should also be established or strengthened. ${ }^{6162}$ Half of US states have minimum price laws, but these were created to protect retailers from predatory business practices, such as larger competitors selling cigarettes below cost. ${ }^{62}{ }^{63}$ Unfortunately, compliance with the laws is not well documented. In addition, so few of the laws exclude industry discounts from the formulae used to calculate the minimum price that the difference between cigarette prices in states with and without these laws was not significant. ${ }^{62}$

Other policies are needed to address the problem of growing profits for tobacco companies and reinvestment in brand marketing. A proposal for price cap regulation recommends that an independent regulatory agency set the maximum price that cigarette companies are allowed to charge for each product, taking into account manufacturing costs and productivity 
savings. ${ }^{64}$ With price cap regulation, differential pricing of cigarette brands would reflect the manufacturers' production costs rather than audience segmentation strategies, thereby limiting the industry's use of price as a marketing tool. ${ }^{64}$ Without additional restrictions on retail pricing, however, retailers could use discount offers to grow target markets and profits.

\section{PLACE}

This section considers the distribution channels for tobacco products, primarily bricks-and-mortar retailers, as well as vending machines and mobile vendors where they are allowed. Economically disadvantaged areas and individuals have greater access to tobacco retailers, although there is more evidence of this in the USA ${ }^{65-68}$ than elsewhere. ${ }^{69} 70$ Tobacco retailer density measures the concentration of places where tobacco products are sold, typically per area or per population. Higher tobacco retailer density is believed to promote smoking by making cigarettes more accessible and available and by increasing environmental cues to smoke. ${ }^{68}$ For example, the more tobacco outlets surrounding high schools in Ontario, Canada, the greater the likelihood that underage smokers purchased their cigarettes. ${ }^{71}$ Higher tobacco outlet density is associated with smoking by adolescents and adults, but the evidence is derived predominately from cross-sectional studies conducted in the USA. ${ }^{66} 6872-74$ Too few studies address tobacco retailer density as a deterrent to cessation ${ }^{75}$ or as a correlate of tobacco-related disease. ${ }^{76}$

WHO identified restricting retailer density as an effective method to reduce alcohol consumption and alcohol-related harms, ${ }^{77}$ and interest in adapting this strategy to tobacco control is growing. ${ }^{78-80}$ Unfortunately, neither the FCTC guidelines nor the FSPTCA promote this strategy beyond restricting vending machines. Eliminating the sale of tobacco products in establishments where smoking is already prohibited, such as airports and hospitality venues, would complement smoke-free laws and reinforce social norms against smoking. Other recommendations to limit the quantity, location and type of tobacco retailers include establishing a minimum distance between them, as well as limiting their proximity to places frequented by children ${ }^{78}$ and to other locations such as hospitals, government buildings and places of worship. ${ }^{80}$

Pharmacies represent a particularly important regulatory challenge. In addition to the symbolic reasons to ban the sale of tobacco products in pharmacies, ${ }^{81}$ it would reduce the number of tobacco retailers (by approximately $7 \%$ in the USA). ${ }^{82}$ Alternatively, pharmacies could be the only outlet where tobacco products are sold. Offering prescription-only cigarettes is consistent with policy objectives to regulate tobacco products like other addictive drugs, as well as to restrict youth access, limit exposure to marketing and reduce retailer density. ${ }^{6183}$ A few US cities ban tobacco sales in pharmacies, but the FSPTCA prevents the FDA from banning tobacco sales in any particular type of retailer and requiring prescriptions for product purchase. ${ }^{84}$

In order to achieve reductions in retailer density, policymakers should also consider incentives for retailers to stop selling tobacco products. ${ }^{80}$ More detailed knowledge of tobacco company contracts with retailers, and a better understanding of what motivates retailers to refuse or abandon the sale of tobacco products, would improve policy development.

\section{IMPLICATIONS FOR POLICY AND PRACTICE}

In spite of its importance to the industry, or perhaps because of it, point of sale is the least regulated channel for tobacco marketing. Existing bans on advertising and promotion are compromised as tobacco companies increasingly shift their marketing dollars to the point of sale. Fewer than 10 countries have passed legislation to ban visible pack displays. More effective regulation of the point of sale is essential to reduce demand for tobacco products as well as their supply. Genuinely comprehensive marketing restrictions require a global ban on all forms of promotion, elimination of packaging and price as marketing tools, and limitations on the quantity, type and location of tobacco outlets.

Accurate knowledge about the number, type and location of tobacco outlets is essential to monitor tobacco industry activity and to enforce comprehensive marketing restrictions. Although this knowledge is best obtained through retailer licensing, the FCTC does not address such regulation and too few countries require it. Subnational policies govern tobacco retailer licensing in Australia, Canada and the USA, and some jurisdictions issue licenses without a fee. ${ }^{61}$ Ireland established a national registry of tobacco retailers and requires a one-time fee $(€ 50) .{ }^{22}$ Alternatively, a renewable license could require an annual fee that reflects the benefit of product sales to retailers as well as the costs to public health. For example, licensing fees could be proportional to tobacco sales revenue for each retailer and uniformly higher than the fee required to sell alcohol, which is comparatively less harmful to public health. License revocation is one possible mechanism to enforce other laws that apply to retailers (marketing, tax, price, sales to minors, smuggling), and should be considered an essential tool for comprehensive tobacco control.

Marketing expenditure data are also needed to enhance existing surveillance systems and to monitor trends in exposure opportunity. Although the largest US cigarette manufacturers are compelled to report annual expenditures for detailed marketing categories, the most recently available data are several years old and do not disclose spending for international markets. ${ }^{56}$ Governments should compel timely disclosure and reporting of industry expenditures for all forms of marketing, as required by the FCTC. In order to support global surveillance, these requests should address international expenditures, reported separately by country.

Comprehensive marketing bans would benefit from additional efforts to build global capacity for surveillance and enforcement. According to WHO, fewer than half of all countries with a 'comprehensive' ban have achieved high compliance, ${ }^{14}$ which suggests that more progress has been made towards enacting marketing restrictions than enforcing them. Poor compliance with marketing restrictions documented in the USA and other high-resourced countries ${ }^{85-87}$ illustrate significant challenges for tobacco control. For example, California pursued successful enforcement action against several tobacco company violations, such as distributing free tobacco products at sporting events where minors competed and mailing free cigarettes to individuals' homes. ${ }^{85}$ The state's tobacco control programme illustrates the importance of shared resources and technical assistance for consistent monitoring of tobacco marketing activities, legal action to deter marketing violations, and dissemination of educational materials and media campaigns to enhance public support and policy adoption.

\section{IMPLICATIONS FOR FUTURE RESEARCH}

Research is needed to encourage policies that address the strategic importance of point of sale, particularly to examine the long-term consequences of banning retail advertising and pack 
displays. Longitudinal studies with larger representative samples are needed to examine how comprehensive regulation interrupts the direct and indirect effects of marketing exposure on adolescent and adult tobacco use. In the absence of comprehensive regulation at the point of sale, there is little evidence as yet that the relationships between marketing exposure, perceived prevalence and intention to smoke are either reduced or eliminated over time. ${ }^{88}$ In addition, such regulation could be expected to reduce craving and urges, particularly among smokers who are more sensitive to external cues.

More research is needed to address the impact of advertising bans in relation to concurrent policy interventions. Comprehensive marketing bans complement mass media campaigns to reduce the salience of pro-smoking cues and to increase antismoking norms. The combination may be particularly effective when intervention messages reflect and reinforce the same content, such as Australia's graphic warning labels and its media campaign against smoking. ${ }^{89}$ Additional methods and measures are needed to capture the potential for synergy. For instance, ecological momentary assessment seems well suited to identify the mix and frequency of pro-tobacco and anti-tobacco messages to which individuals are exposed. A proportional measure or 'share of mind' for pro-tobacco or anti-tobacco cues may better detect the result of industry marketing and tobacco control media campaigns that compete for individuals' attention. Detailed scoring systems are also needed to describe substantial variation in marketing restrictions within and between countries $^{41} 43$ and to illustrate the relative contribution of strong enforcement.

Too little is known about the potential for regulations to either reduce or exacerbate economic or racial/ethnic disparities in exposure to tobacco marketing and tobacco use. A systematic review of multiple population-level interventions concluded that advertising bans showed no differential effects on adolescent smoking by gender or age. ${ }^{90}$ However, the review identified only two studies that reported effects by any sociodemographic variables, and neither intervention regulated any aspect of pointof-sale marketing. More recently, the ITC Four Country Survey observed that adult smokers of different socioeconomic groups reported similar declines in awareness of marketing. ${ }^{13}$ However, most jurisdictions permitted point-of-sale advertising, price discounting or both over the survey years.

Finally, greater monitoring of tobacco marketing practices in low-income and middle-income countries is needed, as well as evidence of the impact of marketing restrictions. Recommendations to improve monitoring of exposure to tobacco marketing and to include other intermediate markers of marketing regulation in global surveillance surveys are consistent with the Millennium Development Goals. ${ }^{91}$ Because economically disadvantaged areas and persons have greater access to tobacco outlets, the potential exists for comprehensive restrictions that address promotion, packaging, price and place to reduce socioeconomic disparities in smoking within and between countries.

\begin{abstract}
Acknowledgements Thanks are due to Maansi Bansal-Travers, PhD, Ellen Feighery, RN, MS, David Hammond, PhD, Nina Schleicher, PhD, and anonymous reviewers for insightful comments on previous drafts. In addition, I wish to thank Amanda Dauphinee and Juliana Doxey, MS, for assistance in preparing the manuscript and table/figure.
\end{abstract}

Funding Preparation of this manuscript was supported in part by the National Cancer Institute, grant CA-67850.

Competing interests None.

Provenance and peer review Commissioned; externally peer reviewed.

\section{REFERENCES}

1. National Cancer Institute. The Role of Media in Promoting and Reducing Tobacco Use. Bethesda, MD: U.S. Department of Health and Human Services, National Institutes of Health, National Cancer Institute, 2008.

2. World Health Organization. MPOWER: A Policy Package to Reverse the Tobacco Epidemic. Geneva, Switzerland: World Health Organization, 2008.

3. World Health Organization. WHO Report on the Global Tobacco Epidemic, 2011 Warning About the Dangers of Tobacco. Geneva, Switzerland: World Health Organization, 2011.

4. Assunta M, Chapman S. A mire of highly subjective and ineffective voluntary guidelines: tobacco industry efforts to thwart tobacco control in Malaysia. Tob Control 2004;13(Suppl 2):ii43-50.

5. Lambert A, Sargent JD, Glantz SA, et al. How Philip Morris unlocked the Japanese cigarette market: lessons for global tobacco control. Tob Control 2004;13:379-87.

6. Mamudu HM, Hammond R, Glantz SA. Project Cerberus: tobacco industry strategy to create an alternative to the Framework Convention on Tobacco Control. Am J Public Health 2008:98:1630-42.

7. Nakkash R, Lee K. The tobacco industry's thwarting of marketing restrictions and health warnings in Lebanon. Tob Control 2009:18:310-16.

8. Freeman B, Chapman S, Rimmer M. The case for the plain packaging of tobacco products. Addiction 2008;103:580-90.

9. Quinn C, Lewis $\mathrm{S}$, Edwards $\mathrm{R}$, et al. Economic evaluation of the removal of tobacco promotional displays in Ireland. Tob Control 2011;20:151-5

10. Assunta M, Chapman S. "The world's most hostile environment": how the tobacco industry circumvented Singapore's advertising ban. Tob Control 2004;13(Suppl 2): ii $51-7$.

11. Carter SM. Going below the line: creating transportable brands for Australia's dark market. Tob Control 2003;12(Suppl 3):iiil87-94.

12. Campaign for Tobacco Free Kids. TobaccoControlLaws.org. 2011. http://www. tobaccocontrollaws.org/index.php (accessed 1 Jul 2011).

13. Kasza KA, Hyland AJ, Brown A, et al. The effectiveness of tobacco marketing regulations on reducing smokers' exposure to advertising and promotion: findings from the International Tobacco Control (ITC) Four Country Survey. Int J Environ Res Public Health 2011;8:321-40.

14. World Health Organization. WHO Report on the Global Tobacco Epidemic, 2009: Implementing Smoke-free Environments. Geneva, Switzerland: World Health Organization, 2009.

15. World Health Organization. WHO Framework Convention on Tobacco Control: Guidelines for Implementation. Geneva, Switzerland: World Health Organization, 2011

16. Thomson G, Hoek J, Edwards R, et al. Evidence and arguments on tobacco retail displays: marketing an addictive drug to children? N Z Med J 2008:121:87-98.

17. Hurt RD, Ebbert JO, Achadi A, et al. Roadmap to a tobacco epidemic: transnational tobacco companies invade Indonesia. Tob Control 2011. Published Online First: 18 August 2011. doi:10.1136/tc.2010.036814

18. Deyton L, Sharfstein J, Hamburg M. Tobacco product regulation-a public health approach. N Engl J Med 2010;362:1753-6.

19. Campaign for Tobacco Free Kids. FDA Authority Over Tobacco: Legal Filings and Decisions. 2011. http://www.tobaccofreekids.org/what_we_do/federal_issues/fda/ legal filings decisions (accessed Dec 2011).

20. Li L, Yong $\bar{H} H$, Borland $\mathrm{R}$, et al. Reported awareness of tobacco advertising and promotion in China compared to Thailand, Australia and the USA. Tob Control 2009;18:222-7.

21. Yong HH, Borland R, Hammond D, et al. Levels and correlates of awareness of tobacco promotional activities among adult smokers in Malaysia and Thailand: findings from the International Tobacco Control Southeast Asia (ITC-SEA) Survey. Tob Control 2008;17:46-52.

22. McNeill A, Lewis S, Quinn C, et al. Evaluation of the removal of point-of-sale tobacco displays in Ireland. Tob Control 2011:20:137-43.

23. Harris F, MacKintosh AM, Anderson S, et al. Effects of the 2003 advertising/ promotion ban in the United Kingdom on awareness of tobacco marketing: findings from the International Tobacco Control (ITC) Four Country Survey. Tob Control 2006;15(Suppl 3):iii26-33.

24. Zaloshnja E, Ross H, Levy DT. The impact of tobacco control policies in Albania. Tob Control 2010;19:463-8.

25. Moodie C, MacKintosh AM, Brown A, et al. Tobacco marketing awareness on youth smoking susceptibility and perceived prevalence before and after an advertising ban. Eur J Public Health 2008;18:484-90.

26. Fielding $\mathbf{R}$, Chee $\mathrm{YY}$, Choi KM, et al. Declines in tobacco brand recognition and eversmoking rates among young children following restrictions on tobacco advertisements in Hong Kong. J Public Health (Oxf) 2004;26:24-30.

27. Braverman MT, Aaro LE. Adolescent smoking and exposure to tobacco marketing under a tobacco advertising ban: findings from 2 Norwegian national samples. $A m$ Public Health 2004;94:1230-8.

28. Fong GT, Cummings KM, Borland $\mathrm{R}$, et al. The conceptual framework of the International Tobacco Control (ITC) Policy Evaluation Project. Tob Control 2006;15 (Suppl 3):iii3-11.

29. Saffer H, Chaloupka FJ. The effect of tobacco advertising bans on tobacco consumption. J Health Econ 2000;19:1117-37.

30. IARC Handbooks of Cancer Prevention. Tobacco Control, Vol. 12. Methods for Evaluating Tobacco Control Policies. Lyon, France, 2008.

31. Centers for Disease Control and Prevention. Global Youth Tobacco Survey (GYTS) Core Ouestions. Atlanta, GA: Centers for Disease Control and Prevention, 
2008. http://apps.nccd.cdc.gov/gtssdata/Ancillary/Documentation.aspx? SUID $=18 D O C T=1$ (accessed 2 Sep 2011).

32. Global Adult Tobacco Survey Collaborative Group. Tobacco Questions for Surveys: A Subset of Key Questions from the Global Adult Tobacco Survey (GATS). 2nd edn. Atlanta, GA: Centers for Disease Control and Prevention, 2011.

33. International Tobacco Control Policy Evaluation Project. 4-Country Wave 7 Recontact Survey. 2011. http://www.itcproject.org/documents/surveys/itc4country/ ques_4c wave7 recontpdf (accessed 2 Sep 2011).

34. Blecher $\mathbf{E}$. The impact of tobacco advertising bans on consumption in developing countries. J Health Econ 2008;27:930-42.

35. Joossens L. GLOBALink: The Effectiveness of Banning Advertising for Tobacco Products. 1997. http://www.globalink.org/tobacco/docs/eu-docs/9710joos.html (accessed 1 Jul 2011).

36. Braverman MT, Svendsen T, Lund KE, et al. Tobacco use by early adolescents in Norway. Eur J Public Health 2001;11:218-24.

37. Galduroz JC, Fonseca AM, Noto AR, et al. Decrease in tobacco use among Brazilian students: a possible consequence of the ban on cigarette advertising? Addict Behav 2007;32:1309-13

38. Pierce JP. Tobacco industry marketing, population-based tobacco control, and smoking behavior. Am J Prev Med 2007;33(Suppl 6):S327-34.

39. Schaap MM, Kunst $A E$, Leinsalu $M$, et al. Effect of nationwide tobacco contro policies on smoking cessation in high and low educated groups in 18 European countries. Tob Control 2008:17:248-55.

40. Levy DT, Benjakul S, Ross $\mathrm{H}$, et al. The role of tobacco control policies in reducing smoking and deaths in a middle income nation: results from the Thailand SimSmoke simulation model. Tob Control 2008;17:53-9.

41. Joossens $\mathbf{L}$, Raw M. The Tobacco Control Scale: a new scale to measure country activity. Tob Control 2006:15:247-53.

42. Hublet A, Schmid H, Clays E, et al. Association between tobacco control policies and smoking behaviour among adolescents in 29 European countries. Addiction 2009;104:1918-26.

43. White VM, Warne CD, Spittal MJ, et al. What impact have tobacco control policies, cigarette price and tobacco control programme funding had on Australian adolescents' smoking? Findings over a 15-year period. Addiction 2011;106:1493-502.

44. Wakefield MA, Morley C, Horan JK, et al. The cigarette pack as image: new evidence from tobacco industry documents. Tob Control 2002;11(Suppl 1):i73-80.

45. Moodie C, Hastings G. Tobacco packaging as promotion. Tob Control 2010;19:168-70.

46. Hammond D. Health warning messages on tobacco products: a review. Tob Control 2011;20:327-37

47. Yong $\mathbf{H H}$, Borland R, Cummings KM, et al. Impact of the removal of misleading terms on cigarette pack on smokers' beliefs about light/mild cigarettes: cross-country comparisons. Addiction 2011;106:2204-13.

48. Siahpush M, Borland R, Fong GT, et al. Socioeconomic differences in the effectiveness of the removal of the "light" descriptor on cigarette packs: findings from the International Tobacco Control (ITC) Thailand Survey. Int J Environ Res Public Health 2011:8:2170-80.

49. Mutti S, Hammond D, Borland R, et al. Beyond light and mild: cigarette brand descriptors and perceptions of risk in the International Tobacco Control (ITC) Four Country Survey. Addiction 2011;106:1166-75.

50. King B, Borland R, Abdul-Salaam S, et al. Divergence between strength indicators in packaging and cigarette engineering: a case study of Marlboro varieties in Australia and the USA. Tob Control 2010;19:398-402.

51. Bansal-Travers $\mathbf{M}, \mathrm{O}^{\prime}$ Connor R, Fix BV, et al. What do cigarette pack colors communicate to smokers in the U.S.? Am J Prev Med 2011:40:683-9.

52. Moodie C, Hastings G. Plain packaging: a time for action. Eur J Public Health 2010;20:10-11.

53. Munafo MR, Roberts N, Bauld L, et al. Plain packaging increases visual attention to health warnings on cigarette packs in non-smokers and weekly smokers but not daily smokers. Addiction 2011;106:1505-10.

54. Thrasher JF, Rousu MC, Hammond D, et al. Estimating the impact of pictorial health warnings and "plain" cigarette packaging: evidence from experimental auctions among adult smokers in the United States. Health Policy 2011;102:41-8.

55. Tobacco Products Scientific Advisory Committee. Menthol Cigarettes and Public Health: Review of the Scientific Evidence and Recommendations. http://www. fda.gov/downloads/AdvisoryCommittees/CommitteesMeetingMaterials/

TobaccoProductsScientificAdvisoryCommittee/UCM247482.pdf (accessed 23 Mar 2011).

56. Federal Trade Commission. Cigarette Report for 2007 and 2008. Washington, DC: Federal Trade Commission, 2011.

57. World Health Organization. GATS (Global Adult Tobacco Survey). 2011. http:// www.who.int/tobacco/surveillance/gats/en/index.html (accessed 6 Sep 2011).

58. Chaloupka FJ, Cummings KM, Morley CP, et al. Tax, price and cigarette smoking: evidence from the tobacco documents and implications for tobacco company marketing strategies. Tob Control 2002;11(Suppl 1):i62-72.

59. Anderson S, Hastings G, MacFadyen L. Strategic marketing in the UK tobacco industry. Lancet Oncol 2002;3:481-6.

60. Cruz TB. Monitoring the tobacco use epidemic IV. the vector: tobacco industry data sources and recommendations for research and evaluation. Prev Med 2009;48(Suppl 1):S24-34.
61. Chapman S, Freeman B. Regulating the tobacco retail environment: beyond reducing sales to minors. Tob Control 2009;18:496-501.

62. Feighery EC, Ribisl KM, Schleicher NC, et al. How do minimum cigarette price laws affect cigarette prices at the retail level? Tob Control 2005:14:80-5.

63. RibisI KM, Patrick R, Eidson $\mathrm{S}$, et al. State cigarette minimum price laws-United States, 2009. MMWR Morb Mortal Wkly Rep 2010;29:385-92.

64. Gilmore AB, Branston JR, Sweanor D. The case for OFSMOKE: how tobacco price regulation is needed to promote the health of markets, government revenue and the public. Tob Control 2010:19:423-30.

65. Hyland A, Travers MJ, Cummings KM, et al. Tobacco outlet density and demographics in Erie County, New York. Am J Public Health 2003;93:1075-6.

66. Novak SP, Reardon SF, Raudenbush SW, et al. Retail tobacco outlet density and youth cigarette smoking: a propensity-modeling approach. Am J Public Health 2006;96:670-6

67. Siahpush M, Jones PR, Singh GK, et al. Association of availability of tobacco products with socio-economic and racial/ethnic characteristics of neighbourhoods. Public Health 2010;124:525-9.

68. Henriksen L, Feighery EC, Schleicher NC, et al. Is adolescent smoking related to the density and proximity of tobacco outlets and retail cigarette advertising near schools? Prev Med 2008;47(2):210-14.

69. Paul CL, Mee KJ, Judd TM, et al. Anywhere, anytime: retail access to tobacco in New South Wales and its potential impact on consumption and quitting. Soc Sci Med 2010;71:799-806.

70. Schneider S, Gruber J, Yamamoto S, et al. What happens after the implementation of electronic locking devices for adolescents at cigarette vending machines? A natural longitudinal experiment from 2005 to 2009 in Germany. Nicotine Tob Res 2011;13:732-40

71. Leatherdale ST, Strath JM. Tobacco retailer density surrounding schools and cigarette access behaviors among underage smoking students. Ann Behav Med 2007;33:105-11

72. McCarthy WJ, Mistry R, Lu Y, et al. Density of tobacco retailers near schools effects on tobacco use among students. Am J Public Health 2009;99:2006-13.

73. Peterson NA, Lowe JB, Reid RJ. Tobacco outlet density, cigarette smoking prevalence, and demographics at the county level of analysis. Subst Use Misuse 2005; 40:1627-35.

74. Chuang YC, Cubbin C, Ahn D, et al. Effects of neighbourhood socioeconomic status and convenience store concentration on individual level smoking. J Epidemiol Community Health 2005;59:568-73.

75. Reitzel LR, Cromley EK, Li Y, et al. The effect of tobacco outlet density and proximity on smoking cessation. Am J Public Health 2011;101:315-20.

76. Lipton R, Banerjee A, Dowling KC, et al. The geography of COPD hospitalization in California. COPD 2005:2:435-44.

77. Babor TF, Caetano R, Casswell S, et al. Alcohol: No Ordinary Commodity-Research and Public Policy. Oxford: Oxford University Press, 2003

78. Ashe M, Jernigan D, Kline $\mathrm{R}$, et al. Land use planning and the control of alcohol, tobacco, firearms, and fast food restaurants. Am J Public Health 2003;93:1404-8.

79. Institute of Medicine. Ending the Tobacco Problem: A Blueprint for the Nation. Washington, DC: National Academy Press, 2007

80. Cohen JE, Anglin L. Outlet density: a new frontier for tobacco control. Addiction 2009:104:2-3.

81. Katz MH. Banning tobacco sales in pharmacies: the right prescription. JAMA 2008;300:1451-3.

82. Henriksen L, Schleicher NC, Winn LE, et al. Impact of banning tobacco sales in pharmacies on the distribution of tobacco outlets: San Francisco, CA. Paper presented at the Society for Research on Nicotine and Tobacco's 17th Annual Meeting; 16-19 February 2011, Toronto, Canada.

83. Pidd H. What A Drag. Iceland Considers Prescription-only Cigarettes. 2011. http:// www.guardian.co.uk/world/2011/jul/04/iceland-considers-prescription-onlycigarettes (accessed 11 Jul 2011).

84. Tobacco Control Legal Consortium. Federal Regulation of Tobacco: Impact on State and Local Authority. 2009. http://publichealthlawcenter.org/sites/default/files/ fda-1.pdf (accessed Dec 2011)

85. Roeseler A, Feighery EC, Cruz TB. Tobacco marketing in California and implications for the future. Tob Control 2010;19(Suppl 1):i21-9.

86. Scott MM, Cohen DA, Schonlau M, et al. Alcohol and tobacco marketing: evaluating compliance with outdoor advertising guidelines. Am J Prev Med 2008;35:203-9.

87. Quedley $\mathbf{M}, \mathrm{Ng} \mathrm{B}$, Sapre $\mathrm{N}$, et al. In sight, in mind: retailer compliance with legislation on limiting retail tobacco displays. Nicotine Tob Res 2008;10:1347-54.

88. Burton D, Graham JW, Johnson CA, et al. Perceptions of smoking prevalence by youth in countries with and without a tobacco advertising ban. J Health Commun 2010;15:656-64

89. Brennan E, Durkin SJ, Cotter T, et al. Mass media campaigns designed to support new pictorial health warnings on cigarette packets: evidence of a complementary relationship. Tob Control 2011;20:412-18.

90. Thomas S, Fayter D, Misso K, et al. Population tobacco control interventions and their effects on social inequalities in smoking: systematic review. Tob Control 2008; 17:230-7.

91. Esson KM, Leeder SR. The Millennium Development Goals and Tobacco Control: An Opportunity for Global Partnership. Geneva: World Health Organization, 2004. http:// www.who.int/tobacco/publications/mdg final for web.pdf 